ENTREVISTA 



\section{CONTRA EL NEOCONSTITUCIONALISMO Y OTROS DEMONIOS ENTREVISTA A JUAN ANTONIO GARCÍA AMADO ${ }^{1}$}

Francisco M. MORA SIFUENTES ${ }^{2}$

Semblanza: Juan Antonio García Amado es uno de los filósofos del Derecho más importantes del mundo latino. Catedrático de Filosofía del Derecho en la Universidad de León (España) $y$ defensor de las tesis clásicas del positivismo jurídico, fue becario de la Deutscher Akademischer Austauschdients para estancias posdoctorales en Alemania. Autor polémico, escribe regularmente en su blog "Dura lex. Política, derecho, sociedad y algo más". Sus líneas de investigación e interés incluyen la tópica jurídica, las teorías del sistema jurídico, la teoría de la norma, la interpretación jurídica, la filosofía del Derecho Penal, la metodología y enseñanza del Derecho, entre otras. De sus contribuciones destacamos: Teoría de las tópica jurídica (Madrid, 1988); Hans Kelsen y la norma fundamental (Madrid, 1997); El Derecho y sus circunstancias (Externado de Colombia, 2010); Un debate sobre la ponderación (con M. Atienza; Lima/Bogotá, 2012).

Semblance: Juan Antonio García Amado, full professor of Legal Theory at the University of Leon (Spain), is one of the most important legal theorists in Spanish-speaking world. Controversial author, he is a defender of the classical theory of Legal Positivism and writes regularly on his blog "Dura lex. Politics, Law, Society and something else". He also was German Exchange Service (DADD) postdoctoral fellow in Germany. His research interest has been focused on issues related to theories of legal system, legal norm, legal interpretation, legal argumentation, foundations of criminal law, legal methodology, legal education, among others. These are some of his publications: Teoría de las tópica jurídica (Madrid, 1988); Hans Kelsen y la norma fundamental (Madrid, 1997); El Derecho y sus circunstancias (Externado de Colombia, 2010); Un debate sobre la ponderación (con M. Atienza; Lima/Bogotá, 2012).

Francisco M. Mora Sifuentes (FMMS): Comencemos por el principio. Podría compartirnos cómo y cuándo decidió estudiar Derecho y si ocurrió algo que fuera determinante para ello. Asimismo, ¿podría decirnos cómo fue la formación (jurídica) que recibió? ¿En qué clima doctrinal, político y social español estaba inserto?

Juan Antonio García Amado (JAGM): Allá por mis diecisiete años me encontraba en la crisis existencial que es (o era) tan común a esa edad. Era un buen estudiante de origen social muy humilde, pero apenas sabía qué quería estudiar. Me atraía la filosofía, pero en la uni-

\footnotetext{
${ }^{1}$ Vaya un agradecimiento al Prof. Dr. Juan Antonio García Amado por aceptar participar en este proyecto, por responder la presente entrevista con diligencia y rapidez notables, no obstante sus múltiples ocupaciones. De la misma forma, gracias a los editores de Ciencia Jurídica por acoger nuevamente este ejercicio.

${ }^{2}$ Profesor-Investigador en el Departamento de Derecho. División de Derecho, Política y Gobierno de la Universidad de Guanajuato (México). Doctor en Derecho por la Universidad Carlos III de Madrid. Miembro del Sistema Nacional de Investigadores (Candidato) del CONACYT. Contacto: fm.mora@ugto.mx
} 
versidad de mi tierra, la Universidad de Oviedo, todavía no se había implantado esa carrera y yo no tenía medios para irme a otro lugar a estudiar. Así que me metí en derecho medio por casualidad y porque suele ser una especie de salida por defecto para los jóvenes que no tienen clara su vocación. Y ahí sucedió lo extraordinario. En la asignatura que entonces se llamaba derecho natural me encontré un profesor fabuloso, Elías Díaz. No era iusnaturalista precisamente. Sus clases me fascinaron y de inmediato me dije que yo quería ser como él y dedicarme a su misma materia, la filosofía del derecho. Ese propósito dio sentido a mi carrera. Elías Díaz se marchó de Oviedo al año siguiente (y con él se fue Manuel Atienza, que entonces empezaba como jovencísimo profesor), pero, al acabar la carrera, conseguí un contrato en Filosofía del Derecho y al poco logré una beca alemana y me marché a Múnich a investigar para mi tesis doctoral. Luego las cosas vinieron rodadas. Bastantes años después, y cuando ya éramos colegas, pude al fin decirle al profesor Elías Díaz lo importante que había sido para mí su ejemplo.

FMMS: En segundo lugar, ¿por qué decidió formarse y, posteriormente, dedicarse a la teoría y filosofía del derecho? ¿Hay etapas en su preparación académica $-v$. gr. hay un antes y un después de sus viajes a Alemania? ¿A quienes considera sus profesores y por qué?

JAGM: Ya he dicho qué papel jugó Elías Díaz, como profesor que despierta mi vocación iusfilosófica, aunque sin saberlo él siquiera en su momento y sin que fuera nunca mi maestro. Cuando terminé los estudios de derecho en Oviedo me atraía mucho la filosofía y me gustaba poco el derecho. Luego esto fue cambiando y ahora me considero ante todo un jurista y prácticamente todas las disciplinas jurídicas me parecen interesantes y todas las ramas del Derecho las veo llenas de problemas teóricos y prácticos apasionantes. Uno de los problemas de la Filosofía del Derecho es que a menudo la cultivan profesores a los que el derecho en realidad no les interesa nada. No es mi caso.

Me licencié en derecho en 1980 y entonces el ambiente iusfilosófico español no era demasiado estimulante. Luego las cosas mejoraron muchísimo. En realidad, yo he sido autodidacta en esto. En Oviedo tuve buenos compañeros, pero ningún maestro académico fuerte. Mis horizontes se abrieron al irme a Alemania y al entrar en contacto con la literatura iusfilosófica alemana. Pero mi timidez de entonces y lo retraído de mi carácter, seguramente por mis orígenes campesinos, me impidieron también estrechar relaciones con maestros alemanes. Mi tutor formal en Múnich era Claus-Wilhelm Canaris, pero creo que no hablé con él más de tres veces, aunque años después traduje al español un libro suyo. También asistía a los seminarios de Arthur Kaufmann, pero tratando de que nadie reparara en mi presencia. Cosas de juventud. Pero cada autor y cada obra iban dejando su huella y me vocación crecía y crecía.

En verdad, y en lo que tiene que ver con mi relación con otros profesores, el mayor disfrute y los mejores momentos llegaron más tarde, cuando pude debatir oralmente o por escrito y en toda clase de eventos con colegas a los que tengo enorme aprecio personal y gran respeto intelectual, como Manuel Atienza, Luis Prieto y unos pocos más.

FMMS: Usted es invitado regularmente a universidades latinoamericanas y europeas. Por ello, me gustaría que nos comparta su impresión sobre la situación de la filosofía del derecho en ambos lados del Atlántico. En términos generales, ¿qué situación guarda, por un lado, 
la teoría y la filosofía del derecho en España y, por otro, la latinoamericana -colombiana, chilena o mexicana-? Asimismo, ¿advierte usted atisbos de decadencia por lo que respecta a España comparada con sus pares europeos -alemanes o italianos? Una cuestión marginal pero interesante, a mi juicio, es que profesores europeos se quejen de que sus pares angloamericanos ni siquiera sepan de su existencia -ya no digamos que los citen en sus trabajos-; denunciando cierto imperialismo de la filosofía jurídica que se genera en Oxford o Harvard, por ponerlo de alguna manera. Sin embargo, no he escuchado a alguno quejarse de la idolatría (veneración, tratos favorables, etc.) que ellos reciben cuando viajan por Latinoamérica, ejerciendo también una suerte de neo-colonialismo jurídico.

JAGM: Son varias cuestiones. Vamos por partes. Empiezo por decir que Latinoamérica ha sido importantísima en mi vida académica. Los académicos hispanohablantes (y podría incluir también a los lusohablantes y los italianos) hemos tardado demasiado en darnos cuenta de que tenemos un gran mercado (en el mejor sentido de la expresión) en el mundo latino, que juntos unos y otros formamos un gran mercado. Yo pasé años de mi vida en Alemania, he disfrutado alguna temporadita en otros países europeos, como Francia o Italia, he viajado mucho y he tratado colegas de múltiples lugares, pero las actividades que han dado mayor sentido a mi vida académica y a mi modesta obra han sido las que he vivido en América Latina, además de en España.

Son muchos los intereses que tenemos en común, no existe la barrera idiomática, compartimos problemas e historias, etc. La obsesión de tanto hispano, de un lado u otro del Atlántico, por encontrar reconocimiento en la doctrina estadounidense o alemana es bastante quimérica y aboca a muchos a la pura melancolía. Además, nosotros, los hispanos o los latinos, no producimos cosas peores, ni muchísimo menos; si acaso, tenemos estilos diferentes, de resultas de que son diferentes las tradiciones doctrinales de las que provenimos. Estoy convencido de que si Dworkin, por ejemplo, hubiese escrito lo mismo que escribió, pero hubiese sido boliviano que enseñaba en La Paz o peruano con docencia en una universidad de Lima o español de la Universidad de León, nadie le habría hecho caso, o poquísimo. Y que si muchos de los que cultivamos la teoría del Derecho en La Paz, Lima, Bogotá, Buenos Aires, Montevideo..., o León, tuviéramos nuestras cátedras en Nueva York u Oxford, no gozaríamos de menos fama que Dworkin.

En cuanto a la idolatría hacia los profesores europeos en Latinoamérica, no le falta a usted razón. Eso es algo que se debería corregir y yo lo he criticado más de cuatro veces, y hasta me he llevado algún disgusto por ironizar sobre esa veneración que a veces es totalmente infundada y acrítica. En todas partes hay de todo y en ocasiones vamos los españoles a Latinoamérica con una actitud despectiva y, como quien dice, a vender a buen precio baratijas teóricas. Pero esa actitud como anfitriones es la que muchas veces tenemos los españoles mismos cuando nos visita un norteamericano, damos por sentado que cualquier cosa que explique va a ser de altísima calidad, y no siempre es así.

En cuanto a la situación de la filosofía del derecho en España, no soy tan optimista como algunos de mis colegas y amigos. Es muy irregular. Cierto que la mejoría durante las dos últimas décadas del siglo XX ha sido enorme. Pero esa mejoría no implica que ahora haya muchísimos iusfilósofos buenos y bien formados, sino que solo supone que hay un índice 
menor de inútiles e ignorantes supinos enseñando esta materia. Pero insisto en que la situación es desigual y habría que analizar universidad a universidad. Hay grupos de iusfilósofos extraordinarios, como los que encontramos en universidades como la de Alicante, la Autónoma de Madrid, la Pompeu Fabra, la de Castilla-La Mancha, la de Girona y alguna más que ahora mismo se me olvidará. Hay universidades en las que el pabellón de la iusfilosofía lo mantienen bien alto dos o tres buenos profesionales, en un contexto hostil, por así decir. De estas podría citar diez o quince. En otras pocas, destaca un iusfilósofo solitario y que lucha contra viento y marea y hasta contra la indiferencia ambiental o la cerrilidad circundante. Y luego están unas pocas facultades de derecho que, en lo que a la iusfilosofía se refiere, son auténticos agujeros negros, antros. En tales sitios sería mucho mejor, para el derecho y para la formación de los estudiantes, que la filosofía del derecho no se enseñara, que tales profesores absurdos no tuvieran a su cargo ninguna asignatura.

En lo que se refiere a la filosofía del derecho en Latinoamérica, la diversidad es enorme de país a país y hasta dependiendo de las zonas de cada país. Hay países, como Argentina o Brasil, que tienen una importante tradición detrás y en los que buenos maestros de antes han abierto camino. También en México. Otros, como Colombia o Chile, cuentan con un buen grupo de profesores más jóvenes que van renovando la teoría del Derecho a base de entusiasmo, esfuerzo y una formación cada vez mejor. En la mayoría de los países el interés es grande, la renovación académica es fuerte y se respira entusiasmo. Creo que en eso, como en tantas otras cosas, el futuro está más en Latinoamérica que en la vieja, cansada, desgastada y desorientada Europa. Baste pensar en lo poco que va quedando de la gran filosofía jurídica alemana, aunque eso a mí me entristezca un poco. Alexy es el último de los grandes, se esté de acuerdo con él o no. Casi todos los que vinieron detrás son del montón y, de promedio, la filosofía del derecho italiana o española seguramente son ahora mismo superiores a la alemana.

FMMS: En lo que viene no seguiré estrictamente el orden de su producción académica. Me gustaría que nos hablara de la influencia que ha tenido en la manida crisis del positivismo jurídico la reductio ad hitlerium y cómo esa falacia se relaciona con una mala comprensión del mismo. En su trabajo Nazismo, Derecho y Filosofía del Derecho, señalaba que la barbarie nacionalsocialista tiene más asidero desde posiciones iusnaturalistas o que a cierto positivismole subyace el valor del individualismo, el parlamentarismo, la democracia y el principio de legalidad, todos ellos incompatibles con el régimen en cuestión. ¿Cuál es su opinión al respecto o qué nuevos elementos tenemos para la crítica? ¿Qué influencia sigue ejerciendo ese momento para nuestra forma de comprender el derecho en la actualidad?

JAGM: Está bien que, por ejemplo en la docencia, usemos la cuestión de si era verdadero derecho un Derecho tan abominable como el de los nazis, o si eran jurídicas normas que hoy nos resultan tan aborrecibles como las que, en cualquier lado, durante milenios permitían la esclavitud o sometían radicalmente a las mujeres al poder de los varones. Bien mirado, si no hay más derecho verdadero que el que no sea muy injusto, podríamos concluir, ufanos, 
que no hay más derecho verdadero que el que hoy tenemos en unos poquitos países de esta llamada cultura liberal-occidental.

Fuera de esos debates siempre interesantes entre iuspositivistas y iusmoralistas, de lo que no me cabe ninguna duda es de que aquel echar las culpas a Kelsen y el positivismo por los excesos jurídicos del nazismo y por la infame actitud de tantos jueces y de casi todos los profesores de derecho después de 1933 en Alemana fue una elaborada artimaña de un extenso grupo de autores alemanes que, con contadísimas excepciones (Radbruch, y poco más) habían sido nazis hasta la médula en tiempos de Hitler (Larenz, Henkel, Maunz, Siebert, Wieacker, Metzger, Scheuner...) o se habían mostrado sumamente complacientes y nada críticos con Hitler y sus secuaces (aquí podríamos nombrar a un buen puñado de maestros de la penalística alemana). Fue una argucia exculpatoria. Alegaron que Kelsen los había convencido de que la ley es la ley y hay poco menos que una obligación moral de cumplir la ley, cualquier ley; y que ellos habían seguido tal consigna porque eran positivistas kelsenianos. Y todo es falso: jamás Kelsen había defendido ni defendería nunca tal idea, y, sobre todo, semejantes sujetos eran fieramente antipositivistas y antikelsenianos en tiempos de Weimar ya (los más viejos), durante el nazismo y los años de la República Federal. Aquella patraña histórica fue luego comprada por iusnaturalistas que, lo mismo en España que en Latinoamérica, defendían todo tipo de dictaduras y detestaban dos elementos habituales en los grandes autores iuspositivistas: sus convicciones democráticas (piénsese en las grandes obras de teoría de la democracia escritas, por ejemplo, por Kelsen, por Ross, por Bobbio o por Ferrajoli, hoy) y un talante filosófico escéptico que impedía a tales positivistas comulgar con las ruedas de molino de esos iusnaturalistas que exaltaban la justicia y los valores objetivos de regímenes como el de Franco o el de tanto dictador latinoamericano.

Los iusmoralistas puede que tengan razón en todo y cabe que los iuspositivistas estén completamente errados en sus teorías, pero, historia en mano, es completamente cierto que la defensa a ultranza de las dictaduras más feroces y de los regímenes más oprobiosos no ha corrido de cuenta de los iuspositivistas nunca o casi nunca, sino de los iusnaturalistas de toda laya. Y, hoy, los regímenes menos democráticos o más autoritarios de América Latina son a veces presentados como suprema expresión de los valores constitucionales más objetivos y de la justicia social redentora, presentación que no suele hacer el iuspositivismo, sino cierto iusmoralismo neoconstitucionalista que se diferencia de los viejos iusnaturalismos eclasiásticos en la indumentaria y en poco más, pero que se sigue solazando ante el poder de unos pocos y que simpatiza escasamente con la soberanía popular rectamente entendida.

FMMS: Hans Kelsen ha pasado de ser venerado, por así decirlo, a ser un autor ninguneado e incluso repudiado. Usted en cambio -sin pasar por alto aspectos problemáticos de sus planteamientos-, siempre ha defendido la importancia de su obra, sosteniendo que no se puede ser antikelseniano sin mentir sobre Kelsen ¿Podría resumirnos los puntos de esa deformación del pensamiento kelseniano?, ¿qué aspectos centrales de su obra, estima, son necesarios rescatar en estos momentos? A menudo se olvida un aspecto central en su biografía: el hecho de ser socialdemócrata en horas de fascismos. Basta recordar su polémica con Carl Schmitt - por no hablar del episodio entre ellos en la Universidad de Colonia y el posterior exilio de 
Kelsen- a propósito de quién debe ser el guardián de la constitución; pero esto apenas si se tiene presente y, me parece, que en esas batallas pocos no estarían con el profesor austriaco.

JAGM: Hoy, hasta los antikelsenianos piensan con las categorías jurídicas, los esquemas o hasta las figuras de Kelsen, igual que hasta los antimarxistas tienen incorporados ciertos esquemas o explicaciones de Marx. La teoría del derecho del siglo XX, y hasta hoy, viene de Kelsen en gran parte, guste o no. Pero eso no es óbice para que muchos elementos de la teoría kelseniana podamos verlos como erróneos o superados. Baste repasar el último libro de Luigi Ferrajoli, La logica del diritto: dieciaporienell’opera di Hans Kelsen (Laterza, 2016). En mi opinión, hay elementos de la obra kelseniana que son ociosos, como su idea de la norma hipotética fundamental, o que tienen que ser seriamente revisados, como su teoría de la cláusula alternativa tácita. Su misma teoría de la validez necesita enriquecerse con ulteriores distinciones más precisas, como la de validez y vigencia o la de validez y existencia, etc., etc. Desde otro punto de vista, seguro que su relativismo ético algo elemental tiene que someterse al escrutinio del debate ético y metaético de nuestros días. Adicionalmente, hay que seguir viendo qué pasa si despojamos a Kelsen de aquel neokantismo que lo hacía asumir ciertos axiomas filosóficos que condicionaban gran parte de su oba, como el de la radical ruptura entre Sein [ser] y Sollen [deber]; etc.

Pero para hacer como es debido toda esa crítica posible hay que empezar por leer mucho y muy en serio a Kelsen, pues, repito, sus teorías están en la base de nuestro modo de ver y practicar el Derecho.

Todo lo anterior supone profesores o investigadores que se tomen en serio su oficio. No se lo toman en serio los que se dedican nada más que a extender errores, prejuicios o infundios sobre la obra o la vida de Kelsen o de cualquier otro autor de cualquier orientación. Y, desde luego, para comprender rectamente tanto la teoría jurídica como la filosofía política de Kelsen no conviene perder de vista cuál era su ideología política. Kelsen encajaría en lo que en estos tiempos llamaríamos un socialdemócrata o un socialista no marxista. Kelsen detestaba tanto los fascismos como el comunismo soviético, a ambos criticó con fuerza y agudeza y por eso sufrió el maltrato habitual que padecieron los mejores y más libres intelectuales del siglo XX que osaron oponerse por igual a todos los totalitarismos. Kelsen, como otros cuantos (Camus, Orwell...), padeció el ataque combinado de totalitarios de derechas y totalitarios de izquierdas. Lo más paradójico es que a un demócrata progresista como él, todos esos que alababan a dictadores de un lado o de otro lo hicieron pasar por autoritario o promotor de las dictaduras. El mundo al revés. Como cuando al judío Kelsen lo quieren los más ignorantes o los peor intencionados presentar poco menos que como cómplice o adalid de Hitler. Vomitivo.

FMMS: En esta misma línea, podría recordarnos parte de la polémica Kelsen-Smend. Este último es un autor fundamental para comprender el giro valorativo de la doctrina y jurisprudencia alemana. ¿Qué importancia tiene en ello la teoría de la integración y, sobre todo, cuáles son sus aspectos más problemáticos? Asimismo, en su trabajo Sobre el neoconstitucionalismo y sus precursores destaca la importancia que tuvo el Kommentar al artículo 1.1 de la Ley Fundamental de Bonn de Günter Dürig y su recepción, con matices, en el famoso fallo Lüth. ¿Cuál es su valoración del comentario y del fallo; qué importancia tienen para nuestras prácticas constitucionales? 
JAGM: La gran mayoría de los constitucionalistas de Weimar eran nostálgicos de las formas imperiales, añoraban un Estado fuerte, recio y nada dado a reconocer derechos de los ciudadanos, tenían un talante autoritario, no veían con buenos ojos el estilo y las reglas republicanas y democráticas de la Constitución de 1919 y desconfiaban por completo de los partidos políticos, los parlamentos y la soberanía popular. De eso se libraban muy pocos, tres o cuatro nada más: Kelsen, Thoma, Anschütz; y, como penalista y iusfilósofo, Radbruch. Muy raramente puede una Constitución sobrevivir al odio o la ojeriza de los constitucionalistas del momento, y eso le pasó a la Constitución de Weimar, a la que sus estudiosos querían eliminar. A los ojos de la posteridad, Schmitt pagó por todos, pero Schmitt no estaba solo, sino que de su antipatía por el estado democrático de derecho participaban casi todos sus colegas de la época.

Constitucionalismo autoritario y con poco afecto al parlamentarismo o a lo que hoy llamaríamos la democracia deliberativa era también el de Smend. Smend mantenía que la esencia del Estado se hallaba en un fuerte sentimiento de pertenencia (integración) de sus ciudadanos, sentimiento o vínculo emotivo que se apoyaba en o se incrementaba por ciertos símbolos (bandera, himno...) o por determinados ritos (desfiles, ceremonias, fiesta nacional...). Por eso al Smend de antes de 1933 el estado fascista italiano le parecía el prototipo de Estado bien integrado, sano, vital, fuerte y pleno.

Kelsen no soportaba ese tipo de metafísicas nacionalistas ni ese género de teorías sustancialistas del Estado. Por eso hace de la obra de Smend una crítica acerada y devastadora, del estilo de la que dirigió también a Schmitt. Para Kelsen, este tipo de constitucionalismo o de teoría del Estado no tenía más función que la función ideológica, en el sentido de falsa conciencia. Se trataría nada más que de incentivar la obediencia ciega de los ciudadanos hacia unos políticos manipuladores y cerriles. Me parece que la historia le dio a Kelsen la razón sobradamente. Me sigue pareciendo interesante, por tanto, la lectura de aquel librito de Kelsen que hace tiempo traduje, El Estado como integración, donde pone patas arriba la teoría de la integración de Smend y su problemático trasfondo ideológico.

Sí hay que decir que Smend fue de los pocos que al final vio las orejas al lobo, uno de los escasos constitucionalistas de aquel tiempo que no se echaron en brazos de Hitler y que durante la dominación nazi no se dedicaron a cantar loas al tirano ni a adular al partido único.

Se suele decir que el constitucionalismo alemán de postguerra provine, por vía discipular, o bien de Smend o bien de Schmitt. La huella de Kelsen en el constitucionalismo alemán no reaparece hasta hace pocas décadas. Creo que eso explica, al menos en parte, hasta el actual neoconstitucionalismo a la manera alexyana, que tiene su antecedente primero en la jurisprudencia de valores y en aquellos autores que, como Dürig, a comienzos de los sesenta ya escribían que la Constitución es un orden objetivo de valores. El neoconstitucionalismo de hoy bebe antes que nada de la síntesis que hace Alexy de la alemana jurisprudencia de valores, por un lado, y de Dworkin, por otro. Esa es la genialidad de Alexy, la de amalgamar dos planteamientos que entre sí no tienen inicialmente mucho que ver. Es obvio que Dworkin no tenía ni remota noticia de lo que habían escrito los constitucionalistas muy conservadores en la Alemania de postguerra, y es evidente que ese constitucionalismo alemán ultraconservador o demócrata-cristiano no se reconocería en la filosofía política progresista de Dworkin. Alexy pasa por encima de esas diferencias y consigue que ese rancio iusmo- 
ralismo del constitucionalismo alemán parezca a la postre progresista, tras vestirlo con algunos ropajes dworkinianos. Y logra también Alexy que, de rebote, el constitucionalismo iuspositivista parezca conservador. El mundo al revés.

En todo el siglo XX, y hasta hoy, no ha existido en el mundo un constitucionalista conservador más hábil e inteligente que Alexy.

FMMS: Uno de los rasgos característicos de cierta teoría del derecho es la apelación a principios como normas jurídicas diferenciadas - moral, funcional o estructuralmente- de las reglas. Sin embargo, tal novedad queda desdibujada por lo que podríamos denominar principialismo de los antiguos. Piénsese en Giorgio Del Vecchio, Roscoe Pound y, fundamentalmente, en Josef Esser para el ámbito continental europeo. ¿Qué parecido tienen las modernas teorías principialistas con la de, por ejemplo, Esser?, ¿existe algo qué las distinga? En segundo lugar, y quizá no del todo pertinente, ¿qué similitudes y diferencias -metodológicas o de otro tipo- encuentra entre las teorías de la tópica jurídica y las teorías de la argumentación jurídica, tan en auge en la actualidad?

JAGM: Curiosamente, el primer artículo que escribí y publiqué fue sobre la teoría del derecho de Josef Esser. Algún día lo rescataré. Yo diría que la relación con el principialismo que hoy domina no es demasiado grande. Me parece que Esser pensaba en algo más cercano a lo que tradicionalmente se han llamado principios generales del derecho, aquellas convicciones morales y sociales, históricamente contingentes, que subyacen a las normas legisladas y cuyo conocimiento y análisis puede ser bien útil como auxilio para la interpretación (en especial, para la interpretación teleológica) o para el colmado de ciertas lagunas. Podemos encontrar un parentesco con lo que luego diría Dworkin (sin tener ni noción de lo que previamente había escrito Esser), pero con la diferencia de que Esser no pretende que esos valores explicativos del contenido de las normas sean, por sí, normas jurídicas genuinas, superiores a las normas legales y perfectamente aptas para derrotar a las normas legales cuando Hércules quiera.

El principialismo actualmente dominante es distinto. El iusmoralismo actual concibe los principios como expresión directa de valores morales objetivos. Ese principialismo se acoge a un realismo moral no naturalista o fuerte y, en tal sentido, los principios vienen a jugar ahora el mismo rol funcional que antes desempeñaban las normas de derecho natural: supremas verdades morales que no pueden dejar de ser, al tiempo, superiores verdades jurídicas. Tal principialismo se torna constitucionalista en cuanto afirma que dichos principios morales verdaderos ya no son derecho meramente porque sí, sino que, además, como derecho se muestran porque han sido constitucionalizados. Entonces el constitucionalismo se hace muy conservador y escasamente democrático. Exactamente igual a como ocurrió en Alemania en los años sesenta del siglo XX. Decir que la esencia de la constitución es axiológica y que su núcleo más auténtico está en una serie abierta o no finita de principios o valores objetivos, de naturaleza moral, sirve para que la doctrina y la judicatura puedan mantener a raya al legislador democrático, a base de anular por contraria a los grandes principios toda reforma legal que amenace la conservación del sistema, el orden establecido, los privilegios de determinados grupos sociales. Lo peculiar de los últimos tiempos es que tal principialismo poco democrático, elitista, algo autoritario y bastante conservador en sus propósitos, se hace pasar por progresista, sobre todo a base de unas pocas sentencias que son ejercicio de lo 
que podríamos llamar jurisprudencia simbólica: algunos tribunales constitucionales declaran algunas libertades bastante irrelevantes (como la de la dosis personal de drogas blandas) con base en principios como el de libre desarrollo de la personalidad, al mismo tiempo que férreamente velan porque se mantengan incólumes los privilegios y las prebendas de algunos grupos, privilegios y prebendas que sí que habría que declarar patentemente inconstitucionales, pero que quedan a buen recaudo en manos de esos jueces tan enamorados de los valores constitucionales y la justicia objetiva.

Baste pensar que una de las consecuencias de que las constituciones actuales sean declaradas expresión de los supremos, verdaderos, universales y definitivos valores o principios morales está en que se ocluye cualquier crítica seria o cualquier propósito de superación de los vigentes órdenes constitucionales. Lo que los viejos marxistas considerarían superestructuras ideológicas y de dominación los actuales neoconstitucionalistas lo dibujan como expresión de la justicia sobre la tierra. Por eso son hiperconservadores en el fondo, porque santifican las constituciones y los ordenamientos vigentes a base de declararlos llenos de moralidad indiscutible. Lo más similar que en estos tiempos hay a aquel llamado positivismo ideológico, que apenas tuvo representantes de Hobbes para acá, es ese neoconsticionalismo moralizante y principialista que declara indiscutiblemente justas las constituciones y pretende que hay obligación moral de acatar punto por punto toda sentencia de una corte constitucional que haya ponderado como Dios manda. Neoconstitucionalismo ideológico lo deberíamos denominar.

En cuanto a la otra cuestión, muy brevemente, diría que el valor de Viehweg y su tópica jurídica es meramente el de precursor de algún aspecto de las actuales teorías de la argumentación. Viehweg es de los primeros que reparan en que una dimensión esencial del derecho es la de praxis y que esa práctica es argumentativa. Pero, en mi interpretación, Viehweg es todavía un irracionalista, pues cree que la práctica jurídica exitosa podemos explicarla como resultante del hábil manejo de ciertos tópicos, pero no piensa que hay una pauta para diferenciar cuáles sean las decisiones judiciales racionales o más racionales, y menos de resultas de alguna regla de racionalidad inmanente al mismo argumentar. Así como Perelman anticipa en puntos importantes a Habermas o Alexy, la doctrina de Viehweg es escasamente normativa, es más bien descriptiva, y sus ambiciones teóricas son mucho menores.

FMMS: Cuando estaba preparando esta entrevista compartí en mis redes sociales una foto de la portada de su Iusmoralismo(s) donde aparecen Alexy, Dworkin y Nino. Antes de preguntarle sobre ella, tengo alguna duda sobre el término: ¿qué pretende designar? ¿Pretende diferenciarlo de neo-constitucionalismo(s), o no? Ahora, y volviendo a la portada, lo desafiante -o si se quiere, perturbador- es que tales autores aparecen como tiros al blanco, con algunos disparos y con sangre. El rango de impresiones que recibí de la misma fue desde desafortunada hasta nefasta... ¿de quién fue la idea de dicha portada? ¿Cómo ha sido recibida entre sus colegas?

JAGM: Esa portada es desafortunada, nefasta, horrible, estúpida y todo cuanto de ese cariz se pueda decir. Yo no la elegí ni la habría elegido nunca. Pero me estuvo bien empleado, por 
exceso de confianza. Soy un poco descuidado en asuntos editoriales, confío mucho y vigilo poco. Craso error, y más cuando no conoces a quien está editando tu obra.

Como me avergüenza un poco esa portada, he rehuido el tema con mis colegas, salvo con los más cercanos, que se han reído bastante a mi costa y me han tomado el pelo. Con razón. Antes de ese incidente ya era bastante escaso mi interés por publicar en papel. Ahora puede que me apetezca aún menos. Lo siento por los editores que no evolucionen, pero el futuro de la publicación científica, doctrinal o académica está en la red. Además, en la red uno controla mucho más el manejo de su propia obra.

En cuanto al término iusmoralismo, pretende ser abarcador para las teorías del derecho que niegan la tesis positivista de la separación conceptual entre Derecho y moral. Llamarlas teorías antipositivistas es designarlas nada más que en negativo y decirles postpositivismos suena pretencioso y algo cursi. Hacía falta un nombre para designar, en lo que tienen en común y se oponen al positivismo, tanto las teorías iusnaturalistas como las no iusnaturalistas. Y no se me ocurrió ni se me ocurre ninguna etiqueta mejor que esa de iusmoralismo. Creo que es perfectamente simétrica a la de iuspositivismo y bien útil para entendernos. Sin más.

FMMS: Los principios concebidos como mandatos de optimización, desarrollados en la Theorie der Grundrechte de Robert Alexy, es uno de los desarrollos más influyentes de los últimos decenios. Ahora, tal concepción llevada hasta sus últimas consecuencias tiene algunas implicaciones que no son muy aceptables. Por ejemplo, que la dignidad humana -se considere regla o principio, da igual- es derrotable en casos particulares (por razones que jueguen en sentido contrario). Varios de sus trabajos van contra la buena prensa de la ponderación para sostener que la misma es contraproducente para nuestros derechos y el estado de derecho. ¿Cuáles son los flancos de crítica más importantes, a su juicio, del principalismo alexyano y de la ponderación que le es consustancial? De hecho, usted ha propuesta una dogmática para la teoría de los derechos ¿podría sintetizarla?

JAGM: Alexy afirma que (a) todas las normas jurídicas son o reglas o principios; que (b) los principios se ponderan o bien contra otros principios o bien contra reglas (en cuyo caso la ponderación es contra el principio subyacente a la regla más el principio de deferencia hacia el legislador legítimo) y que, por tanto, (c) un principio puede tanto derrotar a otro principio como derrotar a una regla. Si eso es así, la conclusión se impone por sí sola: cualquier norma es derrotable, no hay norma (regla o principio) que no pueda alguna vez ser vencida por un principio. Añádase, si se quiere, que los principios son muchos y variados, y que, según Alexy y los alexyanos, hasta los hay implícitos y que aparecen de un día para otro y donde nadie sospechaba que estaban.

Si no hay norma que no sea derrotable por un principio y si el que esa derrota pueda acontecer no depende de que esté en juego un aspecto esencial o no de, por ejemplo, el derecho fundamental en cuestión, sino que depende del peso de la norma amenazada (y del derecho amenazado) y del peso del principio amenazador, eso también tiene una consecuencia insoslayable: no tenemos ni un solo derecho seguro, ni uno; ni un derecho que esté garantizado sin excepción, al menos en su contenido esencial. Por ejemplo, mi derecho a no ser torturado mediante el método de tortura más cruel que quepa imaginar puede una vez (o mil) ser derrotado (puede ser derrotada la norma que lo recoge) por un principio opuesto, 
principio opuesto que igual podrá ser el de defensa de la vida o la integridad física de otros que el de eficaz persecución del delito por el Estado o el de salus republicae summa lex.

Si los tribunales se acogen a la teoría alexyana de las normas y su método decisorio es la ponderación, estamos enteramente a merced de los tribunales y en nada quedará definitivamente protegido ningún derecho nuestro, diga lo que diga la ley o diga lo que diga la mismísima Constitución. Toda norma constitucional con la estructura Todos tienen derecho a d o Los $x$ tienen derecho $a d$, pasa a entenderse bajo esta otra forma: Todos (olos $x$ ) tienen derecho a d..., a no ser en cuantos casos pese más un principio opuesto a $d$. Todos tenemos derecho a no ser torturados (ya que la Constitución prohíbe la tortura) a no ser cuando un principio de más peso justifica que se nos torture; todos tenemos derecho a que no se nos aplique pena de muerte (pues la Constitución la prohíbe), a no ser que en algún caso pese más un principio que justifique la pena de muerte para ciertos delitos o ciertos sujetos. No es sencillamente que nuestros derechos se hagan dúctiles, es que se licúan; o que se evaporan. Serán efectivos nuestros derechos mientras los jueces quieran y cuando los jueces quieran, nada más.

No intentaré aquí sintetizar mi propuesta sobre teoría de los derechos y sobre conflictos entre derechos. Diré simplemente que necesitamos construir dos elementos para trabajar con seriedad y profundidad en este tema: una buena teoría de las normas y una buena teoría de los derechos que, ante todo, diferencie tipos de derechos y, seguidamente, catalogue los modos en que las distintas clases de derechos se interrelacionan. Un ejemplo nada más: los supuestos o aparentes conflictos entre el derecho a la libertad de expresión y el derecho al honor jamás los ha resuelto un juez ponderando (aunque algunas veces se quiera aparentar que se pondera) sino interpretando lo que significa honor. Basta leer aquella sentencia que tanto cita Alexy, la del caso Titanic, para comprobar que así es.

FMMS: Recuerdo que en el seminario celebrado en el CEPC de Madrid en 2013 tras la muerte de Ronald Dworkin, el profesor Francisco Laporta dijo -reconociendo que se trataba de un magnífico escritor- que no recomendaba a los jóvenes leerlo o entrar en sus jardines porque luego era muy difícil sacarlo de ahí; que los abducía en el sentido de Bonorino. Mi pregunta tiene que ver con su figura y su obra: ¿cuál es su valoración general de Dworkin para nuestra disciplina? En segundo lugar, si tuviera que destacar los elementos más criticables de su obra ¿cuáles son y por qué? Finalmente, en su opinión, cuál es (o sería) la respuesta que el positivismo jurídico puede brindar al problema de los desacuerdos teóricos en el Derecho, que, como se sabe, constituye el segundo ataque dworkiniano al positivismo y está contenido en Law's Empire.

JAGM: Me interesa bastante el Dworkin filósofo político. Me interesa poco el Dworkin teórico del derecho. No me parece serio. Me he forzado muchas veces a leerlo, nada más que por curiosidad y tratando de averiguar qué le ven otros que yo no capto. Es marrullero, conceptualmente incoherente, con escasa formación en teoría del derecho y que aprovecha su don literario para reírse del lector en sus mismísimas barbas.

Compréndase que, a partir de esta visión mía de Dworkin, poco estímulo tengo para entrar en detalles o debates. Alguna vez me he detenido a analizar alguna obra suya, pero dudo que reincida en eso. Hay cientos de autores a los que leer y de los que aprender mucho y con cuyas teorías merece la pena batirse. Apuesto a que dentro de treinta años se seguirá hablan- 
do de y escribiendo sobre Kelsen, Hart, Ross, Pound, Olivecrona, Bobbio, Alexy, Atienza, Guastini, Moreso, Chiassoni, Radbruch, Cossio, Schauer, Teubner, Fuller... (repárese en lo caótico y variado de la enumeración), pero Dworkin irá cayendo en el olvido, salvo en ciertos temas filosóficos-políticos. Yo diría incluso que el hechizo ya se está rompiendo, que el desencantamiento ha comenzado y que cada vez son más los que captan, quizá perplejos, que el rey Ronaldo I está desnudo. Dicho sea todo lo anterior con buen ánimo en el fondo hacia un hombre que debió de ser buena persona y que me cae simpático por múltiples razones, incluido algún elemento picaresco.

FMMS: Llegados a este punto estimo indispensable preguntarle sobre su concepción del positivismo jurídico: ¿cuáles son las principales tesis del positivismo jurídico o cómo podríamos caracterizarlo? Usted ha dicho en repetidas ocasiones que se trata de una posición en extremo humilde o simple. Sin embargo, si una teoría ha de evaluarse sobre la base de su capacidad explicativa para describir un objeto, y no tanto justificarlo, ¿no resulta desenfocada la crítica de que el positivismo es una teoría aburrida o, incluso, irrelevante?

JAGM: Lo de que el positivismo es una teoría humilde sí lo asumo, pero lo de que es aburrida o irrelevante no es de mi cosecha, creo, eso suele decirlo mi gran amigo Manuel Atienza. Se ve que mi querido Manuel necesita emociones más fuertes cuando hace teoría del derecho.

Estimo que para caracterizar el iuspositivismo siguen siendo perfectamente válidas las dos notas con que tradicionalmente se lo define, la de la separación conceptual entre derecho y moral y la de las fuentes sociales del derecho. Es una teoría que pretende identificar un objeto, el Derecho, y describirlo, y que no se opone a que ese objeto sea valorado desde múltiples puntos de vista, siempre que la valoración negativa no se entienda como negación del objeto mismo. Un especialista en armas puede identificar una pistola, describirla y explicar cómo funciona. Alguien puede decir que las pistolas son malas, que sirven para matar y que no tendrían que existir. Es un juicio respetable, siempre que no se concluya que la pistola en cuestión no es una pistola porque son malas las pistolas. Una pistola usada para un crimen perverso sigue siendo una pistola; una norma jurídica usada para cometer una injusticia sigue siendo una norma jurídica. Una norma jurídica injusta sigue siendo norma jurídica, igual que una persona injusta sigue siendo una persona o un criminal sigue siendo un ser humano. Tan sencillo como eso. Porque de no ser así, deberíamos preguntarnos por qué llamamos Derecho romano al Derecho de los romanos, que era injustísimo en gran parte de sus contenidos, etc., etc.

El positivismo jurídico, como teoría del derecho, no niega que las normas puedan ser valoradas desde la moral, la política, la economía, la teoría literaria, etc. Solo parte de que cada cosa es lo que es y no deja de ser lo que es en función de quién y cómo la valore. Por lo mismo, el positivismo niega que haya por definición una obligación moral de obedecer las normas jurídicas, idénticamente a como no hay una obligación jurídica de obedecer las normas morales. Porque cada cosa es lo que es y, además, no es propio de gentes en sus cabales confundir la realidad con el deseo o lo que hay con lo que querríamos que hubiera. Una sociedad injusta sigue siendo una sociedad, aunque injusta; un derecho injusto sigue siendo un derecho, aunque injusto. Lo extraño es no verlo así, francamente. Entre otras cosas, porque para cambiar una sociedad injusta o un derecho injusto conviene empezar por no negar 
la realidad ni pensar que la realidad auténtica es otra, distinta de la constatable. Nunca he entendido por qué entre los iusfilósofos hay tanto platónico feliz.

FMMS: Otro parcela del conocimiento jurídico cultivado por usted es la Filosofía del derecho Penal. Algo que se ha observado en últimas fechas en tal ámbito, dado el aumento de la inseguridad -o de la creciente sensación de riesgo-, es laexigencia social de mayor dureza en la represión al crimen. El espectro de propuestas parece ir desde el agravamiento de penas, pasando por medidas inocuizantes hasta el así llamado derecho penal del enemigo de Günter Jakobs. A este respecto, ¿cómo podríamos caracterizar a esta propuesta?; y sobre todo, ¿qué presupuestos ideológico-políticos le subyacen? ¿El enemigo de Jakobs puede vincularse a la schmittiana distinción Freund-Feind?

JAGM: Mi afición o cercanía al derecho penal viene de que desde mis inicios en este oficio siempre he coincidido y tenido amistad con buenos penalistas. En la Universidad de León, en la que llevo veintidós años, celebramos anualmente un seminario internacional de Derecho Penal y Filosofía del Derecho, vamos ya por el decimoctavo. Me han ido gustando cada vez más esos asuntos y últimamente he leído bastante y escrito algo sobre temas tales como al retribucionismo penal, el principio de legalidad penal, la proporción entre gravedad del delito y dureza de las penas o los planteamientos del análisis económico del derecho aplicados al derecho penal. También he escrito algo sobre temas conexos, como el de la llamada justicia transicional. Y hace más tiempo publiqué artículos sobre los dudosos fundamentos luhmannianos de la teoría penal de Jakobs o sobre esa extraña noción de derecho penal del enemigo. Y no hace tanto que descubrí, con una cierta sorpresa derivada de la ignorancia, que los mejores y más importantes debates sobre filosofía del derecho penal no se dan en la Europa continental, sino en Estados Unidos y Gran Bretaña.

La posible relación o conexión entre Schmitt y la idea jakobsiana de derecho penal del enemigo ha sido bien analizada, entre otros, por mi amigo y colega Evaristo Prieto, un verdadero erudito. Nada tengo yo que añadir porque, además, no soy experto en Schmitt y de lo otro sé lo justo. Lo del derecho penal del enemigo lo considero un gravísimo retroceso en la obra última de uno de los más grandes penalistas del siglo XX, G. Jakobs. Es una doctrina internamente incongruente y externamente muy peligrosa.

A lo de la exigencia social de mayor dureza en la represión del crimen yo le añadiría una sola palabrita y diría exigencia social de mayor dureza en la represión del crimen ajeno. Vivimos tiempos de infantilismo galopante y desde el ciudadano común hasta el político más exquisito aplican con descaro la ley del embudo: nada de lo que hagan los míos merece ser castigado, ni de lejos y aun cuando la ley claramente lo tipifique como delito, mientras que cualquier cosilla que a mí me moleste merecería poco menos que cadena perpetua y seguro que vulnera un principio principalísimo y un derecho fundamental mío.

Los profesores penalistas se oponen muy mayoritariamente a ese punitivismo desbocado..., hasta que algún gobierno o ministerio de justicia los llama para asesorar la enésima reforma penal que endurece penas, y entonces acuden raudos y cobran lo estipulado. No quiero ser injusto ni hacer generalizaciones odiosas, pero algún día tendrá la sociología ju- 
rídica que estudiar con calma cierto tipo de ciencia jurídica mercenaria; y no hablo solo de penalistas ni, por supuesto, de la mayoría de los penalistas.

Más allá de estas observaciones, quizá malévolas, me conformo con decir sobre esto que no me apunto al punitivismo, que defiendo el modelo racionalista e ilustrado de sistema penal, al estilo de como actualmente lo fundamenta Ferrajoli, y que soy muy escéptico, mucho, con ciertos desarrollos de movimientos como el de la llamada justicia penal correctiva, que me parecen reaccionarios y huelen a una mezcla de incienso y perfumes de duty free.

FMMS: Una pregunta sobre la enseñanza del derecho. Hace relativamente poco se debatió en España el lugar (o pertinencia) de la clase magistral en la enseñanza universitaria. Recuerdo un artículo de Luis Garicano, profesor español de la LSE, diciendo que la misma estaba out, por así decir, abogando por un cambio de modelo que aprovechara las nuevas tecnologías y, sobre todo,se centrara en conocimientos y competencias técnicas, más ad hoc al mercado. Mi pregunta tiene que ver precisamente con eso, dada la vorágine de modelos, programas, pedagogos, PowerPoint, etc. Desde su punto de vista ¿qué hace a un buen maestro?,¿qué papel están llamadas a jugar las nuevas tecnologías en la enseñanza del Derecho? ¿Cuál ha sido, por ejemplo, su experiencia con su blog Dura lex 3 ?, ¿lo tiene como un medio docente o más bien como un medio de expresión en general?

JAGM: Mi opinión sobre esa cuestión, al hilo del artículo de Luis Garicano y de otro del historiador Enrique Moradiellos, la publiqué en mi blog Dura lex en marzo de 2015, en una entrada titulada sobre las clases magistrales. Ahí me remito. Lo que pienso, resumidamente, es que la calidad de la docencia no depende tanto de métodos o maneras como de la capacidad y formación del docente. De nuestra época de estudiantes todos recordamos clases magistrales extraordinariamente buenas y otras lamentables. Pero raramente una mala clase magistral resulta tan bochornosa como la clase de ese profesor que va leyendo en el PowerPoint, pantalla a pantalla y como si fuera lelo, y que se queda callado y en blanco si se le avería el computador o se va la energía eléctrica.

Lo que hace a un buen maestro es la síntesis de formación, información y entusiasmo. El que sabe poco enseña poco, y el que no entiende bien lo que enseña solo podrá enseñarlo mal. El maestro es el que sabe muy bien de lo que habla, habla de lo que más le gusta o le interesa en el mundo y aplica ante su auditorio, los estudiantes, ese entusiasmo que se vive cuando se da rienda suelta a la vocación auténtica. Lo demás son cuentos chinos, zarandajas, engañabobos. Ni todas las tecnologías del mundo pueden convertir a un profesor ignorante o perezoso en un buen docente, y no hay método pedagógico o didáctico capaz de competir con un maestro que diserta con pasión de los temas que ha estudiado a fondo durante años y años.

La teoría de la enseñanza jurídica y la regulación y evaluación de la enseñanza jurídica han caído en casi todas partes en manos de pobres gentes simples que, a falta de mayores luces o capacidad para empresas más elevadas, se dedican a reglamentar el modo en que han de enseñarse materias de las que ellos no tienen ni remota idea. Me encanta la expresión pedabobos con que en España algunos los describen. Esos bobos son los que, incluso conven-

\footnotetext{
3 http://garciamado.blogspot.mx/ 
cidos, establecen que una buena investigación no puede darse si primero no va un capitulito de formulación de objetivos o si los diversos capítulos no tienen una extensión similar o si no acaba todo en una listita de conclusiones muy finamente expresadas. Paparruchas, pamplinas. La suerte y la edad me han hecho totalmente independiente de esa tropa de cretinos. Pero son los de esa tropa los que en las universidades y ministerios se han adueñado de los comités de evaluación, de los controles de calidad de la investigación y hasta de la selección del personal universitario. Viene a ser como si, de pronto, los más bajitos del país controlaran el baloncesto de la NBA: acaban prescribiendo que todos los jugadores sean pequeños o que los más altos jueguen inclinados, o deciden que las canastas han de ponerse a solo dos metros del suelo para que no resulte vulnerado el libre desarrollo de la personalidad del que quiere jugar a eso pero no ha crecido.

FMMS: La última pregunta que me gustaría formularse consta de dos partes. La primera es que señale los libros que, a su juicio, son indispensables que domine, o sepa manejar, todo aquél interesado en adentrarse en nuestra disciplina. En segundo término, ¿qué consejos daría a alguien que está interesado en formarse una carrera en el ámbito de la filosofía del derecho?

JAGM: Empiezo por el final. El que quiera formarse como filósofo del derecho debería empezar por saber mucho derecho, luego tendría que estudiar a los grandes teóricos del derecho y, una vez que domine los aspectos centrales de lo jurídico en sentido estricto, podrá ir ampliando el círculo de sus intereses y estudios, bien hacia la filosofía política, bien hacia la sociología jurídica, bien hacia la historia de las ideas filosófico-jurídicas, etc. Me atrevería a aconsejar que todo filósofo del derecho se vaya convirtiendo también y simultáneamente en experto en algún área de la dogmática jurídica. Por ejemplo, a mí me gustan muchísimo y recomiendo los temas de responsabilidad civil extracontractual o de derecho de familia, además de los temas penales, por supuesto. El filósofo del derecho que no sabe derecho en serio no es filósofo del derecho. Así de simple es la cosa. Hablará mejor o peor de la vida, la felicidad, la justicia, el mundo, la globalización o el sexo de los ángeles, pero filósofo del derecho no es, porque nadie puede filosofar nada sobre aquello que ignora. El filósofo del derecho que sabe poquísimo derecho es como el viejo cura célibe que pontifica sobre el sexo y sus circunstancias, simple impostura.

¿Lecturas convenientes? Los clásicos, todos los clásicos y de cualquier orientación. ¿Tomás de Aquino? Sí. ¿Kelsen? Sí. En suma, los nombres que a todos se nos vienen a la cabeza cuando pensamos en teoría y filosofía del derecho, incluidos nuestros contemporáneos más influyentes. Y hay que leer bastante fuera de la escuela o secta doctrinal de uno.

Si tuviera que acabar con la recomendación del que me parece el más importante libro de teoría del derecho de las últimas décadas, de muchas décadas, no dudaría: Principia iuris (Trotta, 2011), de Luigi Ferrajoli. Eso sí, prescindiendo de las formulillas y del tercer volumen. 


\section{BIBLIOGRAFÍA SELECTA DE JUAN ANTONIO GARCÍA AMADO ${ }^{4}$}

, (coord.), Razonar sobre derechos, Valencia, Tirant Lo Blanch, 2016.

, Iusmoralismo(s). Dworkin, Alexy, Nino, Lima, Legisprudencia.pe, 2014.

, Razonamiento jurídico y argumentación. Nociones introductorias, León, Castilla y León, EOLAS, 2013.

, Ollero Tasara, A. y Hermida del Llano, C., Derecho y moral. Una relación desnaturalizada, Madrid, Fundación Coloquio Jurídico Europeo, 2012.

, y Atienza, M., Un debate sobre la ponderación, Lima/Bogotá, Palestra/Temis, 2012.

, El Derecho y sus circunstancias. Nuevos ensayos de filosofía jurídica, Bogotá, Universidad Externado de Colombia, 2010.

, (coord.) El Derecho en la teoría social. Diálogo con catorce propuestas actuales, Madrid, Dykinson, 2001.

, La filosofía del Derecho de Habermas y Luhmann, Bogotá, Universidad Externado de Colombia, 1997.

, Hans Kelsen y la norma fundamental, Madrid, Marcial Pons, 1996.

, Teorías de la tópica jurídica, Madrid, Civitas, 1988.

, "Conflictos de derechos: qué son y cómo se resuelven" en: J. A. García Amado (coord.), Razonar sobre derechos, Valencia, Tirant Lo Blanch, 2016.

, “Puede la tortura estar moralmente justificada en algún caso?”, Nuevo Foro Penal, núm. 86, 2016, pp. 13-61.

, "Pidiendo el principio. Dworkin y la teoría del derecho en serio", en: J. M. Sauca (ed.), El legado de Dworkin a la filosofía del Derecho. Tomando el imperio del erizo en serio, Madrid, CEPC, 2015.

, "Interpretaciones complejas y conceptos inciertos" en: P. Bonorino (ed.), Razonamiento jurídico y administración de justicia, Madrid, Bubok, 2013, pp. 49-6o.

, "Prefacio" en: Contra naturam. Hans Kelsen e tradicao critica do positivismo jurídico", de Andityas Soares de Moura Costa Matos, Curitiba, Brasil, 2013.

, "Konstitutionalismus und Recht", en: A. Aarnio, T. Hoeren, S. Paulson y M. Shulte (eds.), Pösitivitat, Normativität und Institutionalität des Rechts. Festschrift für Werner Krawietz zum 80. Geburtstag, Berlín, Duncker \& Humblot, 2013, pp. 677-688.

, "Razones para una teoría normativista de la responsabilidad civil extracontractual” en: C. Bernal y J. Fabra (eds.), La filosofía de la responsabilidad civil. Estudios

\footnotetext{
4 FMMS: La selección se realiza a fin de que el lector pueda encontrar referencias que le ayuden a profundizar en los temas aquí tratados. En cualquier caso, entre sus libros, recomiendo: El Derecho y sus circunstancias. Nuevos ensayos de filosofía jurídica (Bogotá, 2010). Ahí se refleja de manera clara las preferencias teóricas del autor además de que compila parte importante de su producción académica.
} 
sobre los fundamentos filosófico-jurídicos de la responsabilidad civil extracontractual, Bogotá, Universidad Externado de Colombia, 2013, pp. 253-279.

, "Riesgo y Derecho penal. Sobre presupuestos constitutivos del Derecho penal en el Estado de Derecho", Revista Académica, núm. 51, 2011, pp. 83-99.

, “Argumentación, Constitución y derechos", en: Racionalidad, argumentación y decisión judicial, Madrid, Bubok, 2012, pp. 21-30.

, "La Filosofía del Derecho en España hoy. Un balance pesimista", Anales de la Cátedra Francisco Suárez, núm. 44, 2010, pp. 523-538.

, "Neoconstitucionalismo, ponderaciones y respuestas más o menos correctas. Acotaciones a Alexy y Dworkin”, en: M. Carbonell y L. García Jaramillo (eds.), El canon neoconstitucional, Bogotá, Universidad Externado de Colombia, 2010, pp. 367-406.

, “Es realista la teoría de la argumentación jurídica? Acotaciones breves a un debate intenso”, Doxa, núm. 33, pp. 441-45o.

, "Abwägung versus normative Auslegung? Kritik der Anwendung des Verhältnismässgkeitsprinzips als Mittel juristicher Methodik", Rechtstheorie, núm. 40, 2009, pp. 1-42.

, "Metafísicas nacionales", Anales de la Cátedra Francisco Suárez, núm. 42, 2008, pp. 9-30.

, "El liberalismo de Isaiah Berlin. La libertad, sus formas y sus límites", Derechos $y$ Libertades. Revista del Instituto de Derechos Humanos "Bartolomé de las Casas", núm. 14, 2006, pp. 41-87.

, "El obediente, el enemigo, el Derecho penal y Jakobs", Nuevo Foro Penal, núm. 69, 2006, pp. 100-136.

, "Existe discrecionalidad en la decisión judicial", Isegoria, núm. 35, 2006, pp. 151172.

, "La interpretación constitucional", Revista Jurídica de Castilla y León, núm. 2, 2004, pp. 37-74.

, "Filosofía hermenéutica y Derecho", Azafea. Revista de Filosofía, núm. 5, 2003, pp. 191-211.

, "Sobre derechos colectivos. Dilemas, enigmas, quimeras", Revista de la Academia Colombiana de Jurisprudencia, núm. 318, 2001, pp. 103-119.

, "Sobre el argumento a contrario en la aplicación del Derecho", Doxa, núm. 24, pp. 85-114.

, "La teoría de la argumentación jurídica. Logros y carencias", Revista de Ciencias Sociales, núm. 45, 2000, pp. 103-129.

, "Razón práctica y teoría de la legislación", Derechos y Libertades. Revista del Instituto de Derechos Humanos "Bartolomé de las Casas", núms. 10-11, 2000, pp. 299-317.

, “Retórica, argumentación y Derecho", Isegoria, núm. 21, 1999, pp. 131-147. 
, "Ernst Fuchs y la doctrina del Derecho libre", Anuario de Filosofía del Derecho, núm. 14, 1997, pp. 803-825.

, “¿Ductilidad del Derecho o exaltación del juez?”, Anuario de Filosofía del Derecho, núm. 13, 1996, pp. 65-85.

, “Tienen sexo las normas? Temas y problemas de la teoría feminista del Derecho”, Anuario de Filosofía del Derecho, núm. 9, 1992, pp. 10-39.

, "Nazismo, Derecho y Filosofía del Derecho", Anuario de Filosofía del Derecho, núm. 8, 1991, pp. 341-364.

, "Derecho y racionalidad. La teoría del Derecho de Josef Esser", Liber Amicorum -Homenaje al Dr. D. José Pérez Montero, Oviedo, Universidad de Oviedo, 1988, pp. 549-571. 